\title{
Study of Route Stability in MANET using Quality of Services
}

\author{
Sachi Brahmbhatt \\ Department of CSE \\ Rajasthan College Engineering for Women \\ RTU, Rajasthan India
}

\author{
Aishwary Kulshrestha \\ M-Tech Professor \\ Rajasthan College Engineering for Women \\ RTU, Rajasthan India
}

\begin{abstract}
Mobile ad hoc network is collection of mobility nodes which have no infrastructure. They are communicating with each other without central access point or base station. Nodes are randomly a move in network because of that topology is frequently changed. Due to changed topology link between nodes breaks repeatedly. When the link breaks MANET required route discovery process again and which increase the routing load in the network. Some of the recently proposed works consider that quality of matrix is effective to enhance the route stability. In this we studied different published paper which gives the reliable routing protocol which used quality of matrix to enhance the stability of the route and network performance.
\end{abstract}

\section{Keywords}

MANET; route stability; quality of matrix;

\section{INTRODUCTION}

Wireless communication emerged as significant technology for mankind. In which information can transmit without help of wires at anytime and anywhere over the distance .the distance anywhere between few meters such as television to remote or thousands of kilometers such as radio communication. It can be classified into two types 1) infrastructure network 2) ad hoc network. In infrastructure network nodes can communicate through central access point or base station. Cellular network is example of infrastructure wireless network. MANET is collection of mobile nodes which is infrastructure less network. There is no central point to access so nodes can communicate in distributed manner. Because of self-configuring network each node acts as host as well as router. If nodes are not in transmission range, it will connect through Multihop. MANET widely used when infrastructure destroyed or there is no infrastructure such as disaster area, in military operation, rescue, taxi cab network, Emergency network. MANET has some features like easy to deploy network, pear to pear communication and Multihop structure

In MANET, several metrics are used to meet quality of service for different application. According to that search the path from source to destination. The fundamental aspect of route stability is determined as follow:

Sable routes: if we required the maximum throughput and traffic latency reduced then it is necessary to ensure that reliable route connection between source-destination. a route should be selected based on some knowledge of node motion and on a probability model of the path future availability.

Efficient route repair: because of service disruption due to route failure can be avoided by build alternative path before current one break. Estimate of the path duration is need for the recovery of route failure.

Network connectivity: network connectivity and topology are characteristics of MANET which determine by the link dynamics. Network design is critical issue since they determine the system capability to support user communication and their reliability level.

Performance evaluation: the performances achieved by higher-layer protocols such as transport and application protocols and heavily depend on the quality of service metrics which get at the network layer. The frequency and route disruptions have essential impact on TCP behavior as well as on video streaming and VIOP services. Thus characterizing route stability on the basis of evaluates quality of service perceived by the user.

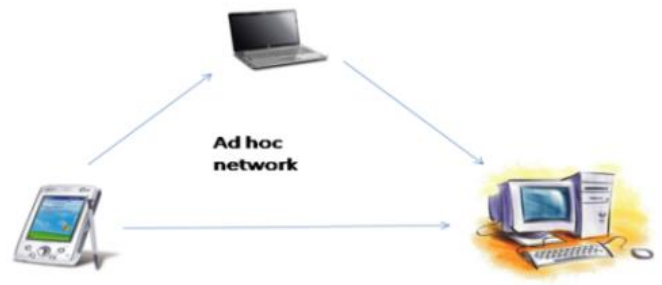

Figure 1. Mobile Ad hoc Network

To design effective and reliable routing strategy in MANET with limited resources is challenging. The intelligent routing tactic is effectively used limited resources and fulfills quality of service to different application and user. In presence of MANET constraints conventional routing algorithm such as distance vector and link state do not scale well. Routing is process to find the path from source to destination and then send data packets on that route [2]. MANET proposed new routing protocols classified on the way the network information obtained.

\section{Proactive (Table Driven) Routing protocol}

\section{Reactive (On-Demand)) Routing protocol}

\section{Hybrid Routing Protocol}

In Proactive or (Table-driven) routing protocols each node maintains the routing information in the network. The Information is periodically updated throughout the network and when topology changes. Each node requires store routing information. Destination Sequenced Distance Vector (DSDV) routing algorithm is example of Proactive routing algorithm [3]. 
In Reactive (on-demand) routing protocols, if node have no communication they do not required to store information and routing activity in the network. The route is created when it on demand or required. When source wants to send the packets to another node it search for the route on demand manner and build the connection in order to transmit and receive the packet it is used flooding mechanism for the route discovery process. (AODV) Ad-hoc on demand distance vector routing and (DSR) Dynamic source routing are the example of the reactive routing protocol [4].

Hybrid routing protocol is combination of reactive and proactive routing protocol. The (ZRP) Zone routing protocol is the example of the hybrid routing protocol that divide the zone into the network. In ZPP supports hierarchical architecture in which each node contains additional information of topologies which required extra memory.

In MANET, routing protocols used intermediate hops to transmit the data. These protocols try to find out the route which contains minimum number of hops to send the packets. Due to topology changed frequently in mobile ad hoc network will take nodes out of each other's transmission range and the route may shatter. Because of minimum hop nodes it tends to fail the route in changing the network condition the minimum hop nodes create a route using routing protocol have weak links so after some time route might be break. If active route breaks then route discovery process initiated which consist of broadcasting route request packets. It will increase routing overhead in the network. If search route is not stable then require to find multiple routes that will affect the performance of the network. If we find a stable route and whose life is longer then there will decrease the discoveries of the route compare to usual and may get the fine packet delivery ratio.

There are several ways to find out to achieve stability in mobile ad hoc network routing protocols. The different ways used different parameters to get the stability such as node residual energy, link expiration time, link available time, node successful data transmission, received signal strength etc. there are various routing protocols but they have no stable link because it choose the link from nearest nodes. Here we surveyed mobile ad hoc network routing protocols which improves link stability and path of the route using several quality of metrics.

\section{RELATED WORK}

Here we introduce various papers related MANET routing protocols which increase the link stability and longer life for the route.
Geetha Nair et.al [5] proposed PLSS-Prediction Based Link Stability Scheme. Stability is significant quality which assures the networks consistency. In this proposed work have four steps to achieve predictable stability are path from source to destination, stability of neighbor node, calculation of mobile node stability and network life time prediction for a particular path. Stability is important parameter for this environment. Here two types of stability are path stability and neighbor stability. Using path stability always provide stable path to sending packets and give the consistency from source to destination .neighbor stability helps to find out consistent neighbor node which used as next hop and calculation of mobility nodes is based on received signal strength. In last predict the network lifetime for the whole network. Simulation results show that PLSS gets the good packet delivery ratio, throughput and stability of the route. PLSS achieves more lifetime of the network than LEAR scheme.

Zheng Sihai et al [6] proposed work QMMRP is new QoS based routing protocol for multicast routing protocol in MANET. This protocol is based on ODMRP on demand multicast routing protocol. In the paper first present the entropy of the node which provides good idea to find stable path in unstable topology network and then QoS model and QMMRP algorithm. This proposed work used limited bandwidth reservation policy and entropy of node to find stable link. NS2 simulator result present QMMRP have better network load than ODMRP. In data experiment QMMRP performs very well compare to ODMRP.

M. Rajendiran et al [7] proposed work is based on mesh based multicast routing protocol to find out stable multiple path from source to destination. In that the node whose fulfill delay requirements can flood the join query message and contributing nodes follow the $\mathrm{M} / \mathrm{M} / 1$ queuing system. The queuing system contains maximum value for queuing and contention delay and this model enhance link stability with contention delay and queuing system. The route is found on the selection of stable nodes which have high stability of link connectivity. The link stability is achieved through using parameters such as distance between neighboring nodes, link received power and link quality. Proposed work performance compare with ODMRP and RODMRP. Simulation result shows that it increases the significant output in terms of throughput and control overhead compared to ODMRP and RODMRP.

\begin{tabular}{|c|c|c|c|}
\hline Algorithm & Description & Result & Tool \\
\hline $\begin{array}{l}\text { Prediction based } \\
\text { Link Stability } \\
\text { Scheme } \\
\text { Mobile Ad } \\
\text { Networks }\end{array}$ & $\begin{array}{l}\text { To achieve stability is aim of this proposed work it } \\
\text { will get through four steps are path from source to } \\
\text { destination, stability of neighbor node, calculation for } \\
\text { mobile node stability and network life time } \\
\text { prediction for particular path. The proposed work } \\
\text { calculates these four steps and then simulates and } \\
\text { compares the performance of the network with } \\
\text { LAER scheme. }\end{array}$ & $\begin{array}{l}\text { Simulation result shows average end to } \\
\text { end delay of PLSS is slightly lower than } \\
\text { LAER. Energy consumption is lower than } \\
\text { LAER. Overhead of the PLSS is lower } \\
\text { than LAER PLSS get good delivery ratio } \\
\text { since it has reliability and stability .PLSS } \\
\text { also have more network lifetime than } \\
\text { LAER scheme. }\end{array}$ & NS3 \\
\hline
\end{tabular}




\begin{tabular}{|c|c|c|c|}
\hline $\begin{array}{l}\text { QoS-Based } \\
\text { Multicast } \\
\text { Routing protocol } \\
\text { in MANET }\end{array}$ & $\begin{array}{l}\text { This proposed work is called QMMRP QoS-Based } \\
\text { multicast routing protocol. Paper presents entropy of } \\
\text { node, QoS model and QMMRP algorithm. It used } \\
\text { entropy of node and bandwidth reservation policy to } \\
\text { search the stable link with enough bandwidth. } \\
\text { Performance of QMMRP simulation with ODMRP. }\end{array}$ & $\begin{array}{l}\text { QMMRP are always higher packet } \\
\text { delivery ratio than ODMRP and its more } \\
\text { in case of large network load. Average } \\
\text { end to end delay is decrease compare to } \\
\text { ODMRP in case of large network load } \\
\text { because OMMRP selects stable link to } \\
\text { transmit data. }\end{array}$ & NS2 \\
\hline $\begin{array}{l}\text { Route efficient } \\
\text { multicast on } \\
\text { demand multicast } \\
\text { routing protocol } \\
\text { with stability link } \\
\text { for MANETs }\end{array}$ & $\begin{array}{l}\text { In this paper multicast routing protocol base on the } \\
\text { mesh network that find the stable multicast path } \\
\text { between source to destination .the node which fulfill } \\
\text { the delay requirements are flood the join query } \\
\text { message. The route is finding through stable } \\
\text { forwarding nodes which have high stability of the } \\
\text { link connectivity. Link stability calculate through } \\
\text { link received power, distance between neighboring } \\
\text { nodes and link quality. }\end{array}$ & $\begin{array}{l}\text { When the number of nodes increases the } \\
\text { throughput of LSODMRP better than } \\
\text { RODMRP and ODMRP and when } \\
\text { mobility increase, throughput of } \\
\text { LSODMRP also better than RODMRP } \\
\text { and ODMRP. LSODMRP also used less } \\
\text { control packets compare to RODMRP and } \\
\text { ODMRP. }\end{array}$ & NS2 \\
\hline $\begin{array}{l}\text { Link Stability in } \\
\text { MANETs } \\
\text { Routing Protocol }\end{array}$ & $\begin{array}{l}\text { This proposed work is focused on the stability of the } \\
\text { link rather than path and speed. Paper shows link } \\
\text { stability concept in high mobility network, best path } \\
\text { choice related to link stability and proposed } \\
\text { algorithm. Link stability table is significant to } \\
\text { implement the protocol and to get efficiency table } \\
\text { will be update beginning of the every route discovery } \\
\text { process and same process is used to identify the } \\
\text { route. This technique is useful to any type of mobile } \\
\text { ad hoc network and when it implemented impact on } \\
\text { the energy consumptions of the nodes. }\end{array}$ & $\begin{array}{l}\text { As a result get the set of routes. Which } \\
\text { represents in the undirected weighted } \\
\text { graph where edge weight is corresponds } \\
\text { to link stability. In output which link has } \\
\text { higher value means a better path. It also } \\
\text { present parameter average shortest path } \\
\text { length summarize the stability behavior of } \\
\text { the entire network. }\end{array}$ & CNET \\
\hline $\begin{array}{l}\text { Providing } \\
\text { Interference- } \\
\text { aware Quality of } \\
\text { Service Support } \\
\text { for ODMRP }\end{array}$ & $\begin{array}{l}\text { In this paper first find out bandwidth consumption } \\
\text { using } 2 \text { hops interference model through conflict } \\
\text { graph then proposed work calculate available } \\
\text { bandwidth using time tag to trace transmission status } \\
\text { and build the routes. ODMRP-IQoS perform very } \\
\text { well in heavy traffic load. }\end{array}$ & $\begin{array}{l}\text { When traffic load reaches } 800 \text { Kbps } \\
\text { ODMRP -IQoS yield } 40 \% \text { packet } \\
\text { delivery ratio while ODMRP packet } \\
\text { delivery ratio reach to zero. ODMRP- } \\
\text { IQoS larger than that of ODMRP. }\end{array}$ & GloMoSim \\
\hline $\begin{array}{l}\text { Fuzzy Agent } \\
\text { based Quality of } \\
\text { Service Multicast } \\
\text { Routing in } \\
\text { Mobile Ad Hoc } \\
\text { Network }\end{array}$ & $\begin{array}{l}\text { This proposed work based on ODMRP. This } \\
\text { proposed work explains fuzzy agent based QoS } \\
\text { multicast routing and approached work and simulate } \\
\text { the result with basic ODMRP.FAQMR choose the } \\
\text { route path using fuzzy which selects suitable route } \\
\text { with longer lifetime estimation. }\end{array}$ & $\begin{array}{l}\text { PDR of FAQMR is higher than ODMRP } \\
\text { for all mobility values. Control overhead } \\
\text { is less in FAQMR than ODMRP .QoS } \\
\text { satisfied path is more when mobility of } \\
\text { nodes less and it decrease when mobility } \\
\text { increases. }\end{array}$ & Matlab 7.0 \\
\hline $\begin{array}{l}\text { LLMRP-Long } \\
\text { Lifetime } \\
\text { Multicast } \\
\text { Routing Protocol }\end{array}$ & $\begin{array}{l}\text { In this paper new mechanism for long life of the } \\
\text { route is proposed which based on ODMRP routing } \\
\text { protocol .main motive of the proposed work to find } \\
\text { the most stable route against the route failure and } \\
\text { increase the route lifetime and decrease the use of } \\
\text { route maintenance to reduce end to end delay and } \\
\text { control overhead. }\end{array}$ & $\begin{array}{l}\text { In future this proposed work evaluates } \\
\text { some result using NS2 simulator. }\end{array}$ & NS2 \\
\hline $\begin{array}{lr}\text { Quality } & \text { of } \\
\text { Service } & \text { Support } \\
\text { and } & \text { local } \\
\text { recovery } & \text { for } \\
\text { Odmrp } & \text { multicast } \\
\text { routing } & \text { in } \\
\text { ODMRP }\end{array}$ & $\begin{array}{l}\text { This proposed work introduced new mechanism for } \\
\text { estimate bandwidth and local recovery approach to } \\
\text { design reliable multicast algorithm. Result shows it } \\
\text { performs well in presence of mobility. }\end{array}$ & $\begin{array}{l}\text { LR-ODMRP more reliable than ODMRP. } \\
\text { QoS-ODMRP improves network } \\
\text { performance than ODMRP by reducing } \\
\text { overhead and utilizing bandwidth. }\end{array}$ & GloMoSim \\
\hline
\end{tabular}

Crescenzio Gallo et.al [8] proposed work is design which focus on network stability rather than speed and path length. This paper presents link stability approach in high mobility network and best path choice according to link stability and proposed work of route discovery. They used the parameters for the link stability is transition frequency of received signal intensity $(\mathrm{dBm})$ and signal intensity itself. In proposed work link stability table is crucial for design and implement the protocol. Table will be updated at starting of every route discovery process to optimize efficiency and used the same procedure to identify the route. The result shows that this simple technique is used for any type of mobile ad hoc network, speed and discovery. And this technique also fruitful to study when implemented impact on energy consumption of the nodes (at the percentage of general ad hoc network). 
Yao $\mathrm{Yu}$ et.al [9] is proposed ODMRP-IQOS present interference- aware of QoS support for ODMRP. Due to growth of multimedia application quality of service is important feature of MANET. This paper investigates QoS and bandwidth consumption in ODMRP routing protocol with 2 hops interference model. This work first investigates the bandwidth consumption via conflict graph then proposed ODMRP-IQoS support for ODMRP.ODMRP-IQoS evaluate the available bandwidth by time to tag to search the transmission status and build the route with enough bandwidth for allocating stream. Results shows that ODMRPIQoS performs very well in relatively heavy traffic scenario and QoS of the stream with reasonable bandwidth consumption are guaranteed in ODMRP-IQoS.

V.R.Budyal et al. [10] proposed on demand fuzzy logic agent based multicast routing scheme in MANET that fulfill the required quality of service in group communication. In MANET multicast routing is used to save bandwidth and energy while sending the data to multiple receivers and it also supports real time multimedia applications. Multicast routing with Quality of service requirements such as bandwidth, end to end delay, jitter and energy will provide efficient services in multimedia application. in this proposed work some agents follows the sequances.1) build the QoS mesh network and its identification of QoS mesh nodes is based on parameters like speed ,residual power of node and delay between two nodes by using fuzzy interface system.2) path of the route for receiver to transmit packet is selected from a QoS mesh.3)mobile agent are employed to maintain QoS path when route fail or link breaks and also facilitate to join or leave the group. The author

Evaluates performance parameter such as packet delivery ratio, control overhead and QoS satisfied path. The proposed work gives better performance than on demand multicast routing protocol.

Abdulmalek AL-Hemyari et al. [11] paper presents a new proposed algorithm, long lifetime multicast routing (LLMRP) protocol which is based on, On-demand multicast routing protocol (ODMRP). In last few years many researchers have proposed new mechanism on multicast routing. ODMRP proposed to decrease the control overhead and improve the scalability, but the main drawback of ODMRP increase the control overhead when it use in large size network. Another proposed algorithm (LSLP) link stability and lifetime prediction based QoS aware routing for MANET it improves the link stability and lifetime and decreasing the cost, but the control overhead and the cost of link stability will increase. EODMRP with motion adaptive refresh algorithm is extant ion of ODMRP which reduce the control overhead up to $50 \%$ and packet delivery ratio as the prime ODMRP. Another LSMLR proposed algorithm is significant improvement but the control overhead is still high. Author propose stable multicast routing protocol which is based on ODMRP(ondemand multicast routing protocol). The proposed algorithm changes the mechanism of route discovery and data transmitting to increase the use of route that consist of stable mobile nodes. This algorithm decreases the requirement of route maintenance mechanism and improves the stability of route by increasing the route lifetime. This algorithm finds the most stable route from the multiple routes that create by mesh mechanism between the source and receivers. The main parameters of proposed algorithm are distance between mobile nodes, overall packet delay and coverage area by each mobile node. The main aim of this proposed algorithm is enhance the route lifetime and reduce the control overhead and end to end delay, decrease the use of route maintenance mechanism.

Mhadi Effat Parvar et.al [12] In MANET limited bandwidth and dynamic topology is primary issues and reliable multicast also plays important roles in many MANET applications. ODMRP was design for multicast routing in MANET. In this paper a new method for estimating bandwidth for multicast routing and also a new technique for QOS routing in ODMRP by create an acceptable estimation of required and available bandwidth by the author. They also propose local recovery approach to design reliable multicast algorithm. Author applied techniques on ODMRP and evaluated in simulator scenarios. The simulation shows that LDODMRP is more reliable than ODMRP, and it has better performance even the speed of multicast group member increase.QOS ODMRP increase the output compared to ODMRP and also reducing control overhead and utilizing bandwidth.

\section{CONCLUSION AND FUTURE WORK}

In MANET routing protocols are find route on the basis of minimum hops. It will create a weak link and frequently break the route. Repeating the numbers of failure route increase the routing discovery process and it will lead routing load in the network so required to search alternate parameter to find out route rather than minimum hops to improve the stability of the route. There are various parameters to find out stable route but recent paper present received signal strength is better parameter to find out stable route. In this paper we also studied the different proposed work which shows received signal strength improves the stability of the route compare to some existing MANET routing protocol find the stable route. The stable route remain longer time and also reduce the control overhead, increase the packet delivery ratio and throughput of the network by using received signal strength.

In future we are working on multicast routing protocol (ODMRP) on- demand multicast routing protocol to enhance the network performances. We are using combination of QoS metrics to enhance the link and route stability and performance of network in terms packet delivery ratio and average end to end delay. We can also secure multicast routing protocol from various attacks that mitigate the network throughput.

\section{ACKNOWLEDGMENTS}

Our thanks to researchers for contribute their information to students and professors to get the more knowledge about subject.

\section{REFERENCES}

[1] Arati and Dr.S.S. Tayagi, Study of MANET , International Journal Advanced Research and in Computer Science and Software Engineering, Volume 3, Issue 5, May 2013.

[2] Robinpreet Kaur \& Mritunjay Kumar Rai, A Novel Review on Routing Protocols in MANETs, Undergraduate Academic Research Journal (UARJ), Volume-1, Issue-1, 2012.

[3] C. E. Perkins and P. Bhagwat, Highly dynamic destination-sequenced distance-vector routing (DSDV) for mobile computers, Proceedings of X the SIGCOMM '94, August 1994, pp. 234-244.

[4] C. Perkins, E. Belding-Royer and S. Das ,Ad hoc OnDemand Distance Vector (AODV) routing, RFC3561, July 2003. 
[5] Geetha Nair and Dr.N.J.R.Muniraj, Prediction Based Link Stability Scheme for Mobile Ad hoc Network, International Journal of Computer Science 2012.

[6] Zheng Sihai, Li Layuan, Guo Lin, QoS-Bases Multicast Routing Protocol in MANET, 2012 International Conference on Industrial Control and Electronics Engineering.

[7] M.Rajendiran, S.K. Srivatsa, Route efficient on demand multicast routing protocol with stability link for MANETs, Indian Journal of Science and Technology, Vol. 5, No. 6, June 2012, pp.2866-2871.

[8] Crescenzio Gallo, Miche le Perilli, and Michelangelo De Bonis, Link Stability in MANET Routing Protocols, the fourth International Conference on Mobile Ubiquitous Computing, Systems, Services and Technologies, 2010.
[9] Yao Yu, Yu Zhou, and Sidan Du, Providing Interferenceaware Quality of Service Support for ODMRP, 2009 Asia Pacific Conference on Information Processing.

[10] V.R.Budyal, S.S.Manvi, S.G.Hiremath, Fuzzy Agent based Quality of Service Multicast routing in mobile Ad hoc Network, 2012 International conference on Advance in Mobile Network Communication and its Applications.

[11] Abdulmalek al-hemyari, Mahamod Ismail, Rosilaah Hassan Sabri Saeed, Improving Link Stability of Multicast Routing Protocol in MANETs, 2013 Journal of Theoretical and Applied Information Technology.

[12] Mehdi Effat Parvar, Amir Dareshorzadeh, Mehdi Dehghan, Mohammad Reza Effat Parvar, Quality of Service Support and Local Recovery for ODMRP Multicast Routing in Adhoc networks, 2008 IEEE. 